\title{
EFFECT OF WOOD-FIBER GEOMETRY SIZE ON MECHANICAL PROPERTIES OF WOOD-FIBER FROM Neolamarckia cadamba SPECIES REINFORCED POLYPROPYLENE COMPOSITES
}

\author{
${ }^{1} *$ MOHD SUKHAIRI MAT RASAT, ${ }^{1}$ RAZAK WAHAB,${ }^{2}$ AMRAN SHAFIE, ${ }^{3}$ AG AHMAD MOHD \\ YUNUS, ${ }^{1}$ MAHANI YUSOFF, ${ }^{1}$ SITTI FATIMAH MHD. RAMLE AND ${ }^{1}$ ZULHISYAM A.K. \\ ${ }^{1}$ Universiti Malaysia Kelantan (UMK), Jeli Campus, 17600 Jeli, Kelantan \\ ${ }^{2}$ Universiti Teknologi Mara (UiTM) Pahang, 26400 Bandar Tun Abdul Razak Jengka, Pahang \\ ${ }^{3}$ Universiti Malaysia Sabah (UMS), 88400 Kota Kinabalu, Sabah
}

Corresponding author: sukhairi@umk.edu.my

\begin{abstract}
Using natural wood-fiber as reinforcement in commercial thermoplastics is gaining momentum due to its high specific properties and renewable resources. In this study, the effect of wood particle geometry size on mechanical properties of thermoplastics composite was investigated. The wood species that has been chosen is Kelempayan species (Neolamarckia cadamba) and reinforced with polypropylene using fiber geometry size of 75 and $250 \mu \mathrm{m}$. Thermoplastic composites were produced from two types of ratio (30:70 and 10:90) between wood-fiber and polypropylene. Static bending and tensile strength were tested. The result showed that wood-fiber from $75 \mu \mathrm{m}$ geometry sizes with ratio of 30:70 between wood-fiber and polypropylene was most suitable in producing thermoplastic composites. The geometry sizes of wood particle as well as the ratio between wood-fiber and polypropylene were found to influence the mechanical properties of the thermoplastic composites.
\end{abstract}

KEYWORDS: Wood-fiber, Polypropylene, Thermoplastic composites, Wood particle geometry size, Neolamarckia cadamba species, Mechanical properties.

\section{Introduction}

Wood industry is one of the major contributors to the Malaysian economy where vast amounts of wood based products were exported. The development in these industries had been driven primarily by the abundance of wood waste products. Wood composites have been produced to mock and substitute for solid wood in a variety of different forms (i.e. fibers, particles, strands, veneer or lumber) that are adhesived with thermoset or thermoplastic resins. The resulting material is very similar to solid wood in many aspects and typically takes a simple product form such as flat plates or rectangular beam elements (Rowell, 1994).

To date, the problem of environmental issues had been one of our main concerned, where some of environment pollutants are from the wood-based industry, mainly in the form of sawdust. These wood waste products were burnt openly or used as fuel-wood to operate the boilers in factories. In order to minimize this problem, this study was initiated to utilize the sawdust as filler in thermoplastic composites. The wood particulates or wood-fibers with different geometry size and ratio were dispersed in a matrix of polymers polypropylene. 
The objective of this study was to investigate the mechanical properties of the thermoplastic composites that can be affected by different sizes of particle filler (wood-fiber) and different ratio between the filler loading with polypropylene content and to maximize the use of wood residues to produce modified wood-based products and most importantly to reduce the environment pollutions.

\section{Materials and methods}

\section{Source of materials}

A defect free Kelempayan (Neolamarckia cadamba) tree was obtained from Learning Reserved Forest at Universiti Teknologi MARA (UiTM) which is situated in Bandar Tun Abdul Razak Jengka, Pahang. The tree was selected based on good form, long straight bole and decay-free. The diameter of the tree at breast height was $25 \mathrm{~cm}$ with $25 \mathrm{~m}$ height. The top portion (20\% from total tree height) of the tree was selected to pursue this study. The Kelempayan tree was then debarked and cut into several small portion before being chipped. The chips were then shredded by a flaker machine to produce small particles of wood-fiber. Particles were then screened and classified into two mesh sizes $(75$ and $250 \mu \mathrm{m})$ using an Oscillating Multideck Screen Classifier. Oven drying method was used to maintain the moisture content of these particles at $10-12 \%$. Particles sizes of Kelempayan wood-fiber to polypropylene ratio were calculated using thermoplastic composites composition as shown in Table 1.

Table 1. Thermoplastic composites composition manufactured

\begin{tabular}{ccccc}
\hline $\begin{array}{c}\text { Particles sizes of } \\
\text { wood-fiber }(\mu \mathrm{m})\end{array}$ & \multicolumn{2}{c}{ Ratio of filler loading $(\%)$} & $\begin{array}{c}\text { Weight of } \\
\text { wood-fiber }(\mathrm{g})\end{array}$ & $\begin{array}{c}\text { Weight of } \\
\text { polypropylene }(\mathrm{g})\end{array}$ \\
\hline 250 & 30 & 70 & 600 & 1400 \\
& 10 & 90 & 200 & 1800 \\
\hline 75 & 30 & 70 & 600 & 1400 \\
& 10 & 90 & 200 & 1800 \\
\hline
\end{tabular}

\section{Thermoplastic composites manufactured}

Thermoplastic composites were produced in a two-stage process. For the first stage, wood-fiber particles were compounded into pellets at 10 and $30 \%$ by weight for each particles size group using dispersion extruder machine. The barrel temperatures ranged from $190-200{ }^{\circ} \mathrm{C}$ from feeding to die zones. Screw speed was set at $240 \mathrm{rpm}$ and melt pressure at the die varied from 15 to 25 bar depending on wood-fiber particles content.

For the second stage, thermoplastic composites test specimens were produced using hot press followed by cold press machine in the conditions shown in Table 2. Specimens were made according to American Society for Testing and Materials (ASTM) standard specifications for static bending and tensile strength tests (Table 3). Specimens were stored in controlled conditions at $50 \%$ relative humidity and $23^{\circ} \mathrm{C}$ for 40 hours prior to testing according to ASTM standard. 
Table 2: $\quad$ Hot and cold press machines setting

\begin{tabular}{llcc}
\hline & & Pressure (psi) & Duration (minutes) \\
\hline Hot press & Static bending strength & 720 & 4 \\
& Tensile strength & 1000 & 2 \\
\hline Cold press & Static bending strength & 2 & $2-5$ \\
& Tensile strength & 10 & $2-5$ \\
\hline
\end{tabular}

Table 3: $\quad$ Specimens for static bending and tensile testing

\begin{tabular}{lccc}
\hline Test & Mould size $(\mathrm{mm})$ & Weight of pellets $(\mathrm{g})$ & Testing size $(\mathrm{mm})$ \\
\hline Static bending strength & $240 \times 150 \times 6$ & 216 & $150 \times 25 \times 6$ \\
Tensile strength & $350 \times 350 \times 2$ & 144 & $150 \times 10 \times 2$ \\
\hline
\end{tabular}

\section{Mechanical properties of thermoplastic composites}

Evaluation for mechanical properties was carried out on thermoplastic composites (Kelempayan species reinforced polypropylene). The evaluation was conducted according to ASTM D790-03 and ASTM D638-03 standard respectively. Mechanical properties of thermoplastic composites (Kelempayan species reinforced polypropylene) were tested using the following method; Static bending strength includes modulus of elasticity (MOE) and modulus of rupture (MOR) besides tensile strength for modulus of rupture (MOR).

Mechanical properties of wood are qualification of its resistance to exterior forces which tend to deform its mass (Erwinsyah, 2008). The resistance of wood to such forces is governed by their magnitude and the manner of loading (bending, compression, shear, tension, etc.). Tsoumis (1991) stated that wood exhibited different mechanical properties in different growth directions, therefore it is mechanically anisotropic. According to Bowyer et al. (2004), mechanical properties are usually the most important characteristics of wood product used in structural applications. Structural application is any constructional usage which is governed by the strength property which is the primary criteria for material selection. Structural usage of wood products includes floor joint and rafters, wall sheathing and sub-flooring (Erwinsyah, 2008).

\section{Static bending strength}

The static bending tests were conducted using Instron Machine. The dimensions of thermoplastic composites sample for static bending test were according to ASTM D790-03 standard for MOE and MOR (ASTM, 2003). Bending testing was done to determine the strength of thermoplastic composites due to stress or load that hit on the testing sample using three points bending loading system at a speed of $10 \mathrm{~mm} / \mathrm{min}$ and $96 \mathrm{~mm}$ of span. The tests were stopped when the samples started to break. The proportional limit with ultimate load and deflection were recorded, the MOE and MOR were automatically calculated by the computer connected to the machine.

The static bending strength refers to test performed in which a bending stress is applied to the specimen to determine the stiffness or modulus of elasticity (MOE) of the specimen as well as the amount of force required to cause the specimen to fail, expressed as the modulus of rupture (MOR) (Erwinsyah, 2008). Static bending strength of wood is usually expressed in term of the MOR (Erwinsyah, 2008). These properties are the most important parameters which usually are used for engineering purposes. 


\section{Tensile strength}

The objective of tensile test is to determine the strength of bonding between the wood particles and plastic (polypropylene) in accessing the value of MOR using Instron Machine Testing and was carried out by using ASTM D638-03 standard (ASTM, 2003). The specimen was supported on a span of $96 \mathrm{~mm}$ similarity for static bending. Tensile strength will reflect how good will the material reacts under a certain pressure of forces. Tensile test is also known as tension test and was conducted until a complete failure or break was accorded.

\section{Results and discussions}

\section{Mechanical properties of the thermoplastic composites}

With respect to the mechanical properties of the thermoplastic composites (Kelempayan species reinforced polypropylene), several mechanical properties were tested including static bending strength (MOE and MOR) and tensile strength (MOR). These testing were carried out on the basis of ASTM standard for the mechanical properties evaluation. Mechanical properties of the thermoplastic composites (Kelempayan species reinforced polypropylene) were investigated on the effect of wood particle geometry size and ratio between wood-fiber from Kelempayan species with polypropylene.

\section{Static bending strength of the thermoplastic composites}

In order to investigate the static bending strength of the thermoplastics composite (Kelempayan species reinforced polypropylene), the data were analyzed to examine the effect of wood particle geometry size $(75$ and $250 \mu \mathrm{m})$ and ratio between wood-fiber with polypropylene (30:70 and 10:90) to the MOE and MOR. Results of static bending test including MOE and MOR strength were presented in Tables 4 and 5.

The thermoplastic composites from wood-fiber size $75 \mu \mathrm{m}$ recorded the highest value for both MOE and MOR in static bending strength for every ratio between wood-fiber and polypropylene either of 10:90 or 30:70. In addition, the ratio of 30:70 possessed the highest value for each wood-fiber size either of 75 or $250 \mu \mathrm{m}$.

Table 4: $\quad$ Modulus of elasticity (MOE) static bending strength of thermoplastic composites

\begin{tabular}{ccc}
\hline Wood-fiber size $(\mu \mathrm{m})$ & Ratio & MOE (MPa) \\
& (wood-fiber : polypropylene) & \\
\hline 75 & $10: 90$ & 37686.20 \\
& $30: 70$ & 49481.44 \\
& $10: 90$ & 31441.74 \\
Control & $30: 70$ & 40429.51 \\
& $0: 100$ & 25646.02 \\
\hline
\end{tabular}

According to the obtained results of static bending test which is summarized in Table 4 for MOE, the average values of the $75 \mu \mathrm{m}$ wood-fiber size group for ratio 10:90 and 30:70 were 37686.20 and $49481.44 \mathrm{MPa}$ respectively. In addition, the average values MOE for $250 \mu \mathrm{m}$ of wood-fiber size group were 31441.74 and $40429.51 \mathrm{MPa}$ for 10:90 and 30:70 ratio groups, respectively. The average value MOE for the control sample was $25646.02 \mathrm{MPa}$. 
Table 5: Modulus of rupture (MOR) static bending strength of thermoplastic composites

\begin{tabular}{ccc}
\hline Wood-fiber size $(\mu \mathrm{m})$ & Ratio & MOR $(\mathrm{MPa})$ \\
& (wood-fiber : polypropylene) & \\
\hline 75 & $10: 90$ & 112.09 \\
& $30: 70$ & 124.80 \\
250 & $10: 90$ & 99.58 \\
& $30: 70$ & 121.44 \\
Control & $0: 100$ & 97.51 \\
\hline
\end{tabular}

Besides MOE, the wood strength upon reaching the breaking point was able to recover to its original shape (known as MOR). The test results of MOR for the thermoplastic composites (Kelempayan species reinforced polypropylene) at the different wood-fiber sizes and ratios were presented in Table 5.

Based on the results in Table 5, the MOR of the thermoplastics composite (Kelempayan species reinforced polypropylene) were gradually decreasing from 75 to $250 \mu \mathrm{m}$ of wood-fiber size for each ratio groups (10:90 and 30:70), while the opposite was true for 10:90 to 30:70 wood-fiber size group ratio $(75$ and $250 \mu \mathrm{m})$. The average values MOR for $75 \mu \mathrm{m}$ of wood-fiber sized group were 112.09 and 124.80 MPa for 10:90 and 30:70 ratio groups, respectively. While the average MOR for $250 \mu \mathrm{m}$ of wood-fiber sized group were 99.58 and $121.44 \mathrm{MPa}$ based on ratio groups of 10:90 and 30:70, respectively. The average value MOR for the control sample was $97.51 \mathrm{MPa}$.

These results clearly demonstrated that the values of the thermoplastic composites (Kelempayan species reinforced polypropylene) for MOE and MOR strength of static bending were decreasing for wood-fiber sized of 75 to $250 \mu \mathrm{m}$ for every ratio group (10:90 and 30:70) and decreasing from ratio of 30:70 to 10:90 for each wood-fiber size group (75 and $250 \mu \mathrm{m}$ ), respectively. According to Shao et al. (2012), the mechanical properties for static bending strength both for MOE and MOR decreased with increasing sizes of wood-fiber. This degradation was due to the increased in moisture adsorption (Shao et al., 2012), where the woodfibers were poorly bonded with polypropylene plastic matrix or other particles when larger wood-fiber was used.

Tables 4 and 5 illustrated the facts that wood-fiber content was highly correlated to both MOE and MOR properties. In general, high wood-fiber content yields materials will yield high rigidity and strength. This statement was in agreement with Hassine et al. (2009), based on their study on the effect of wood-fiber content on rigidity and strength properties of White Cedar particle-based composite.

\section{Tensile strength of the thermoplastic composites}

Table 6 illustrated the tensile strength average values of $75 \mu \mathrm{m}$ wood-fiber sized groups for $10: 90$ and 30:70 ratio group were 2465.47 and $3167.55 \mathrm{MPa}$, respectively. For the $250 \mu \mathrm{m}$ wood-fiber sized group, the results were 2119.29 and $2851.93 \mathrm{MPa}$ for 10:90 and 30:70 ratio groups, respectively. These result clearly illustrated tensile strength decreased from wood-fiber sized 75 to $250 \mu \mathrm{m}$.

In addition, the ratio group of 30:70 was higher in MOR value compared to 10:90 for wood-fiber sized group for both sized groups of either 75 or $250 \mu \mathrm{m}$. 
Table 6: $\quad$ Modulus of rupture (MOR) tensile strength of thermoplastic composites

\begin{tabular}{lll}
\hline Wood-fiber size $(\mu \mathrm{m})$ & $\begin{array}{l}\text { Ratio } \\
\text { (wood-fiber : polypropylene) }\end{array}$ & MOR $(\mathrm{MPa})$ \\
\hline 75 & $10: 90$ & 2465.47 \\
& $30: 70$ & 3167.55 \\
250 & $10: 90$ & 2119.29 \\
& $30: 70$ & 2851.93 \\
Control & $0: 100$ & 1922.52 \\
\hline
\end{tabular}

Mechanical property for tensile strength (MOR) decreased with increasing size and similar trend was exhibited for static bending strength property. Kuo et al. (2009) reported that tensile strength of thermoplastic composites decreased slightly with increasing wood-fiber size. This phenomenon was also observed in static bending strength, due to poorly bonded woodfibers with polypropylene plastic matrix or other particles when larger wood-fibers were utilized (Shao et al., 2012).

The ratios between wood-fiber with polypropylene were influenced by tensile strength and similarly were observed in static bending strength. Hassine et al. (2009) reported that tensile strength of the thermoplastic composites increased steadily with wood-fiber content. These results were supported by the previous studies on wood-fiber thermoplastic composites carried out by Robin \& Breton (2001) and Park \& Balatinecz (1997).

\section{Analysis of variance (ANOVA) on mechanical properties of thermoplastic composites}

Table 7 showed the ANOVA for mechanical properties of the thermoplastic composites of Kelempayan species reinforced polypropylene. The analyses were conducted to determine whether there were significance differences between mechanical properties (MOE for static bending strength and MOR for static bending including tensile strength) with wood-fiber sizes of 75 and $250 \mu \mathrm{m}$ and ratio between wood-fiber and polypropylene of the thermoplastic composites.

Based on ANOVA (Table 7), there were significant differences between mechanical properties (static bending strength (MOE and MOR) and tensile strength (MOR)) with the woodfiber sizes and ratios between wood-fiber with polypropylene factors at $1 \%$ level. Based on this study, all the mechanical properties showed significant differences with wood-fiber sizes and ratios between wood-fiber with polypropylene. These results clearly illustrated that wood-fiber sizes and ratio wood-fiber to polypropylene composition directly influenced the mechanical properties strength of the thermoplastic composites. 
Table 7: $\quad$ ANOVA on mechanical properties of thermoplastic composites

\begin{tabular}{lcrrrr}
\hline Source of variance & $\begin{array}{l}\text { Dependent } \\
\text { variable }\end{array}$ & $\begin{array}{r}\text { Sum of } \\
\text { square }\end{array}$ & Df & $\begin{array}{c}\text { Mean } \\
\text { square }\end{array}$ & F-Ratio \\
\hline Size & MOEb & 1.9499 & 1 & 1.9499 & $34.44 * *$ \\
(wood-fiber) & MORb & 209.828 & 1 & 209.828 & $21.83 * *$ \\
& MORt & 363651.0 & 1 & 363651.0 & $29.42 * *$ \\
\hline Ratio & MOEb & 1.86795 & 2 & 9.33973 & $164.97 * *$ \\
(wood-fiber : polypropylene) & MORb & 3413.1 & 2 & 1706.55 & $177.52 * *$ \\
& MORt & 6.11293 & 2 & 3.05646 & $247.27 * *$ \\
\hline
\end{tabular}

Note: $* * \quad=\mathrm{p} \leq 0.01$

$\mathrm{MOEb}=$ Modulus of elasticity for static bending

$\mathrm{MORb}=$ Modulus of rupture for static bending

MORt $=$ Modulus of rupture for tensile

Based on ANOVA (Table 7), all mechanical properties vary significantly with woodfiber sizes and wood composition, which conformed to that observed by Hassine et al. (2009), Robin \& Breton (2001) and Park \& Balatinecz (1997). Shao et al. (2012) observed a decreased in mechanical property both static bending and tensile strength with increasing wood-fiber size, and the data of this study conformed to that observation.

\section{Correlation coefficient on mechanical properties of thermoplastic composites}

The correlations among size (wood-fiber) and ratio (wood-fiber : polypropylene) with mechanical properties of the thermoplastic were presented in Table 8. Correlations were observed between mechanical properties (MOE/MOR for static bending strength and MOR for tensile strength) of thermoplastic composites with size (wood-fiber) and ratio (wood-fiber : polypropylene). Negative correlation at $1 \%$ significant level were observed between ratio (woodfiber : polypropylene) with MOE of static bending strength $(r=-0.9184)$, MOR of static bending strength $(r=-0.9202)$ and similarly for MOR tensile strength $(r=-0.9324)$. However, for MOE and MOR of static bending strength and MOR of tensile strength against wood-fiber size were negatively correlated at $5 \%$ significant level.

The negative correlation between size (wood-fiber) and ratio (wood-fiber : polypropylene) with mechanical properties (MOE and MOR for static bending strength and MOR for tensile strength) indicated that the strength of thermoplastic decreased from 75 to 250 $\mu \mathrm{m}$ size wood-fiber as well as for the ratio between wood-fiber to polypropylene from 30:70 to 10:90 (Table 7). The sizes of wood-fiber and ratio between wood-fiber with polypropylene influenced the mechanical properties (MOE/MOR for static bending strength and MOR for tensile strength) of the thermoplastic composites.

These positive correlation illustrated (Table 7) that mechanical properties were interrelated between MOE with MOR of static bending strength, MOE of static bending strength with MOR of tensile strength and MOR of static bending strength with MOR of tensile strength $(\mathrm{p} \leq 0.01)($ Table 7$)$. 
Table 8: Correlation analysis on mechanical properties of thermoplastic composites

\begin{tabular}{|c|c|c|c|c|c|c|}
\hline \multirow{2}{*}{ Size } & & Size & Ratio & $\mathrm{MOEb}$ & MORb & MORt \\
\hline & & 1 & $0.0000 \mathrm{~ns}$ & $-0.2970 *$ & $-0.2328 *$ & $-0.2313 *$ \\
\hline \multicolumn{2}{|c|}{ Ratio } & & 1 & $-0.9184 * *$ & $-0.9202 * *$ & $-0.9324 * *$ \\
\hline \multicolumn{2}{|c|}{ MOEb } & & & 1 & $0.9465 * *$ & $0.9627 * *$ \\
\hline \multicolumn{2}{|c|}{ MORb } & & & & 1 & $0.9699 * *$ \\
\hline \multicolumn{2}{|c|}{ MORt } & & & & & 1 \\
\hline \multirow[t]{6}{*}{ Note: } & $* *$ & $=\mathrm{p} \leq 0.01$ & & & & \\
\hline & $*$ & $=\mathrm{p} \leq 0.05$ & & & & \\
\hline & ns & $=$ not signi & & & & \\
\hline & Mc & $=$ Modulus & lasticity for & c bending & & \\
\hline & Mc & $=$ Modulus & upture for $s$ & bending & & \\
\hline & $\mathrm{MC}$ & $=$ Modulus & pture for te & & & \\
\hline
\end{tabular}

\section{Conclusions}

Mechanical properties of the thermoplastic composites were clearly influenced by wood-fiber variability as observed by variations in fiber surface properties and wood specific gravity as reported by Hassine et al., (2009). Thermoplastic composites made from wood-fiber in small sized $(75 \mu \mathrm{m})$ exhibited higher mechanical properties compared to bigger sized wood-fiber (250 $\mu \mathrm{m})$. Increased wood-fiber sizes decreased the strength and stiffness of the thermoplastic composites. Thermoplastic composites made from high yield wood-fiber composition possessed better static bending and tensile strength properties. Increased wood-fiber composition improved the strength and stiffness of the thermoplastic composites.

\section{References}

ASTM D638-03. (2003). Standard test method for tensile properties of plastics. West Conshohocken: ASTM International.

ASTM D790. (2003). Standard test method for flexural properties of unreinforced and reinforced plastics and electrical insulating materials plastics. West Conshohocken: ASTM International.

Erwinsyah. (2008). Improvement of Oil Palm Wood Properties Using Bioresin. A Ph.D. Dissertation. Technische Universität Dresden. Germany.

Bowyer, J. L., Shmulsky, R. and Haygreen, J. G. (2004). Forest Product and Wood Sciences An Introduction (4 ${ }^{\text {th }}$ Edition). Blackwell Publishing Company.

Hassine, B., Ahmed, K., Patrick, P. and Alain, C. (2009). Effects of fiber characteristics on the physical and mechanical properties of wood plastic composites. Journal of Composites. Part A 40: 1975-1981.

Kuo, P. Y., Wang, S. Y., Chen, J. H., Hsueh, H. C. and Ysai, M. J. (2009). Effects of material compositions on the mechanical properties of wood-plastic composites manufactured by injection molding. Journal of Mater Des. 30(9): 3489-3496. 
Park, B. D. and Balatinecz, J. J. (1997). Mechanical properties of wood-fiber/toughened isotactic polypropylene composites. Journal of Polym Compos. 18(1): 79-89.

Robin, J. J. and Breton, Y. (2001). Reinforcement of recycled polyethylene with wood fibers heat treated. Journal of Reinf Plast Compos. 20(14): 1253-1262.

Rowell, R. M. (1994). Chemical of Solid Wood. Subtitled by Suhaimi Muhammed and Halimathon Hj Mansor. Kuala Lumpur: Dewan Bahasa dan Pustaka.

Shao, Y. L., Tsu, H. Y., Sheng, F. L. and Te, H. Y. (2012). Optimized material composition to improve the physical and mechanical properties of extruded wood-plastic composites (WPCs). Journal of Construction and Building Materials. 29: 120-127.

Tsoumis, G. (1991). Science and Technology of Wood - Structure, Properties and Utilization. New York: Van Nostrand Reinhold. 